\title{
Computational insight into the mechanism of the irreversible inhibition of monoamine oxidase enzymes by the anti-parkinsonian propargylamine inhibitors rasagiline and selegiline
}

\author{
Tana Tandarić and Robert Vianello*
}

Computational Organic Chemistry and Biochemistry Group, Ruđer Bošković Institute, Bijenička cesta 54, HR10000 Zagreb, Croatia. Phone: +385 14561117. Fax:+385 14680084. E-mail: robert.vianello@irb.hr

\begin{abstract}
Monoamine oxidases (MAO) are FAD-containing flavoenzymes that catalyze the degradation of a range of brain neurotransmitters, whose imbalance is extensively linked with the pathology of various neurological disorders. This is why MAOs have been the central pharmacological targets in treating neurodegeneration for more than 60 years. Still, despite this practical importance, the precise chemical mechanisms underlying the irreversible inhibition of the MAO B isoform with clinical drugs rasagiline (RAS) and selegiline (SEL) remained unknown. Here we employed a combination of MD simulations, MM-GBSA binding free energy evaluations, and QM cluster calculations to show the MAO inactivation proceeds in three steps, where, in the rate-limiting first step, FAD utilizes its N5 atom to abstracts a hydride anion from the inhibitor $\alpha$ $\mathrm{CH}_{2}$ group to ultimately give the final inhibitor-FAD adduct matching crystallographic data. The obtained free energy profiles reveal a lower activation energy for SEL by $1.2 \mathrm{kcal} \mathrm{mol}^{-1}$ and a higher reaction exergonicity by $0.8 \mathrm{kcal} \mathrm{mol}^{-1}$, the former in excellent agreement with experimental $\Delta \Delta G^{\ddagger}$ EXP $=1.7 \mathrm{kcal} \mathrm{mol}^{-1}$, thus rationalizing its higher in vivo reactivity over RAS. The calculated $\Delta G_{\mathrm{BIND}}$ energies confirm SEL binds better due to its bigger size and flexibility allowing it to optimize hydrophobic $\mathrm{C}-\mathrm{H} \cdots \pi$ and $\pi \cdots \pi$ interactions with residues throughout both of enzyme's cavities, particularly with FAD, Gln206 and four active site tyrosines, thus overcoming a larger ability of RAS to form hydrogen bonds that only position it in less reactive orientations for the hydride abstraction. Offered results elucidate structural determinants affecting the affinity and rates of the inhibition reaction that should be considered to co-operate when designing more effective compounds devoid of untoward effects, which are of utmost significance and urgency with the growing prevalence of brain diseases.
\end{abstract}

KEYWORDS: irreversible inhibition, monoamine oxidase, hydride transfer, antiparkinsonian drugs, neurodegeneration, flavoenzymes 
FOR TABLE OF CONTENTS USE ONLY

Computational insight into the mechanism of the irreversible inhibition of monoamine oxidase enzymes by the anti-parkinsonian propargylamine inhibitors rasagiline and selegiline

Tana Tandarić and Robert Vianello

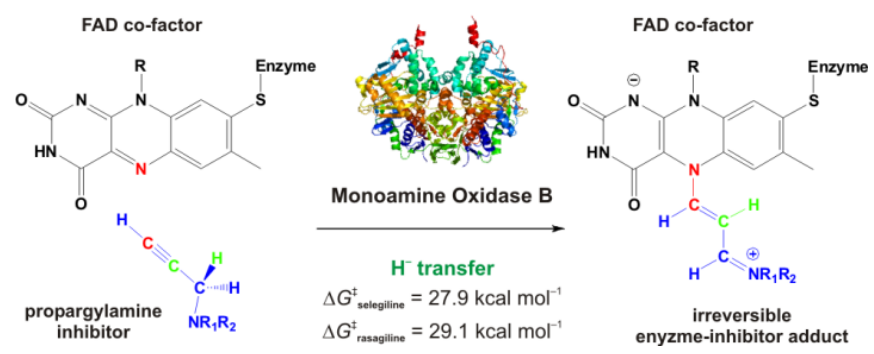




\section{INTRODUCTION}

Monoamine oxidase (MAO) is a flavin adenine dinucleotide (FAD)-containing enzyme that metabolizes a range of biogenic and dietary amines, as well as monoamine neurotransmitters, such as dopamine, serotonin and adrenaline, in both the central nervous system and peripheral tissues. ${ }^{1}$ The rapid degradation of these molecules ensures the proper functioning of synaptic neurotransmission and is critically important for the regulation of brain functions. Since monoaminergic signaling is regarded as one of the key mechanisms for the modulation of mood and emotion, as well as the control of motor, perceptual and cognitive functions, any imbalance in the concentration of these neurotransmitters in the brain has been identified in most, if not all, neuropsychiatric and neurological diseases.

MAO exists in two known and fully characterized isoforms, namely MAO A and MAO B, ${ }^{2}$ which share around 70\% sequence identity and the same FAD co-factor (Figure 1) covalently attached at a conserved cysteine residue. ${ }^{3}$ Their deep active site cavities are different in volume and shape ${ }^{4}$ conferring very different substrate and inhibitor specificities. ${ }^{5}$ The chemical reaction catalyzed by MAO involves the oxidation of the amine moiety via oxidative cleavage of the substrate $\alpha-\mathrm{CH}$ bond with the ensuing generation of an imine intermediate. This pathway is accomplished by the reduction of FAD to $\mathbf{F A D H}$ that is reoxidized back to FAD by molecular oxygen, with simultaneous hydrogen peroxide release. Later, the imine intermediate is hydrolyzed by a nonenzymatic pathway yielding the related aldehyde and either ammonia (with primary amines) or a substituted amine (from secondary amines), ${ }^{5}$ according to the overall equation:

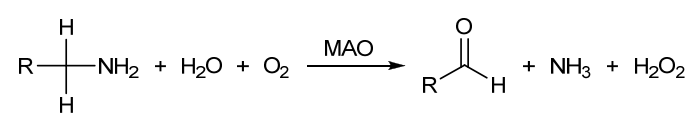

As such, the byproducts of MAO-mediated reactions include a number of potentially neurotoxic agents. ${ }^{6-8}$ Consequently, a prolonged excessive activity of MAO enzymes may be conducive to mitochondrial damages and neurodegenerative disturbances. In keeping with these premises, the progress in MAO inhibition has led to important breakthroughs in the therapy of several psychiatric and neurological diseases, ranging from mood disorders to Parkinson (PD) and Alzheimer diseases (AD). ${ }^{9}$ Furthermore, the characterization of MAO knockout mice ${ }^{10}$ has revealed that the inactivation of this enzyme produces a number of functional and behavioral alterations, some of which may be harnessed for therapeutic aims. The modulation of brain and behavior by MAO inhibitors ${ }^{11}$ has, therefore, made the design of new inhibitors a medicinal chemistry challenge in both academia and industry for the last 60 years. ${ }^{12}$ 

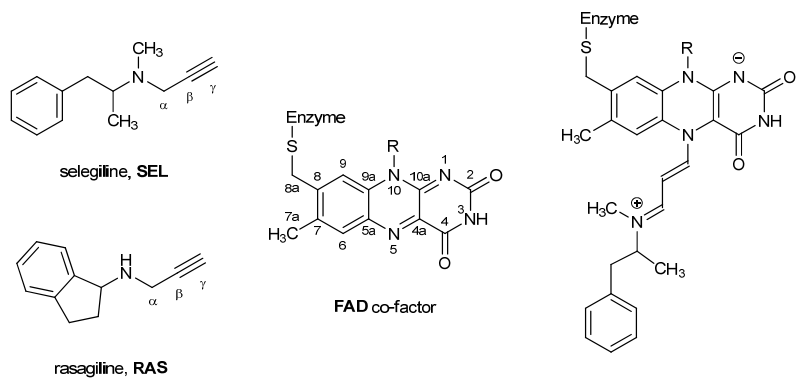

Figure 1. Chemical structures of systems discussed in this work together with the relevant atom numbering.

The development of MAO inhibitors started with the non-selective reversible inhibitors ipronazid and phenelzine, ${ }^{13}$ yet these were shown to be associated with diverse adverse effects, including liver toxicity ${ }^{14}$ and the so-called "cheese reaction", consisting in severe, potentially lethal hypertensive crises following the consumption of foods rich in tyramine, ${ }^{15}$ which prompted research to characterize selective inhibitors. Since tyramine oxidation occurs exclusively by intestinal MAO A, selective MAO B inhibitors, such as selegiline (SEL) and rasagiline (RAS), revealed that these were efficacious for the PD treatment, yet being free from this potential interaction, which warrants their use without the restriction of a low-tyramine diet. ${ }^{16}$ Inhibiting MAO B not only prolongs the half-life of dopamine and extends its neurotransmission effect for relieving motor symptoms, it also prevents the MAO B-mediated oxidative damages during dopamine degradation, ${ }^{17}$ which is further prompted by the fact that more than $80 \%$ of MAO in the human brain is of the B subtype. ${ }^{18}$ Yet, the anti-MAO B drugs are still linked with significant untoward effects, ${ }^{19}$ and treat only the symptoms of a disease not the cause, which underlines the necessity for the design of new and more potent compounds.

The majority of MAO inhibitors in current use are mechanism-based irreversible inhibitors, ${ }^{9,20}$ whose activity relies on forming a covalent bond with the enzyme, which is the most successful way of inhibiting MAO B in vivo. ${ }^{21}$ Selegiline (L-deprenyl, SEL) was the first such irreversible drugs to be clinically used and has been on the market since the late 1980s. ${ }^{22}$ Its adduct with N5 on FAD (Figure 1) has been identified both chemically ${ }^{23}$ and in the crystal structure of MAO B. ${ }^{24}$ However, SEL is metabolized to L-amphetamine-like metabolites which can cause appetite suppression and insomnia. ${ }^{25}$ In addition, amphetamines inhibit dopamine's transport to vesicles, ${ }^{26 a-b}$ making it susceptible to the autooxidation in the cytoplasm, ${ }^{26 \mathrm{c}}$ giving rise to the additional source of the reactive oxygen species. As a safer alternative, in the first decade of this century the propargyl analogue rasagiline (RAS) was developed and approved, which features the same mechanism of action. ${ }^{27}$ Unlike SEL, RAS does not give amphetamine-like metabolites and is devoid of the neurotoxic side effects of the other drug, while its major metabolite 1 -aminoindan is also neuroprotective, ${ }^{28}$ allowing a lower daily dose, which is all why it is more widely used nowadays. In general, the clinical practice confirmed that propargylamine MAO B inhibitors are effective 
and safe medications that provide symptomatic benefit for Parkinson patients from early to late stages of disease. $^{29}$

Today, there is a broad spectrum of therapeutic possibilities for the utilization of MAO inhibitors. Novel routes of administration, as well as pro-drugs which are converted to active inhibitors by brain enzymes, are promising directions for future progress. Research efforts over last years offered many classes of potent and more selective compounds, ${ }^{30-32}$ as well as understanding structural determinants affecting the selectivity among isoforms. ${ }^{33}$ However, for a rational prediction of more effective systems, what is seriously missing are details of a precise chemical mechanism of the inhibition reaction. This would make path for a design of mechanism-based drugs as transition-state analogues that are likely to improve the selectivity and efficacy in neurodegenerative diseases, which might consent the use of lower therapeutic doses, thus strongly diminishing possible adverse effects. To address this point, in this work we carried out molecular dynamics simulations ${ }^{34}$ to investigate the binding of SEL and RAS within the MAO B active site and underline residues predominantly responsible for the successful binding. This is followed by QM cluster calculations ${ }^{35}$ at the DFT level to elucidate, to the best of our knowledge, for the first time in the literature, the exact mechanism leading from bound inhibitors to the corresponding N5(FAD)-adducts (Figure 1).

\section{RESULTS AND DISCUSSION}

Molecular Dynamics Simulations. Molecular dynamics simulations were performed to inspect the conformational flexibility of RAS and SEL within the MAO B active site, and to reveal specific interactions governing the binding (full computational details are given in the Supporting Information). The calculated binding free energies, $\Delta G_{\mathrm{BIND}}$, for both inhibitors are presented in Table 1 together with their decomposition into contributions from individual residues. Illustrative snapshots from MD trajectories are shown in Figure 2.

It turns out $\Delta G_{\mathrm{BIND}}$ for both inhibitors are negative and indicate favorable binding. Yet, the value for SEL is more exergonic, showing it is better positioned within the active site, being in line with a trend in the measured $K_{\mathrm{i}}$ and $\mathrm{IC}_{50}$ values (Table 1). It is noteworthy that our $\Delta G_{\mathrm{BIND}}$ energies appear in good qualitative agreement with those by Mangiatordi et al., ${ }^{33}$ who reported data between -13 and $-22 \mathrm{kcal} \mathrm{mol}^{-1}$ for the two reversible chromene MAO inhibitors, although the obtained $\Delta G_{\mathrm{BIND}}(\mathbf{S E L})=-31.83$ and $\Delta G_{\mathrm{BIND}}(\mathbf{R A S})=-28.36 \mathrm{kcal} \mathrm{mol}^{-1}$ are likely overestimated in absolute terms. This is a known limitation of the MM-GBSA approach, as extensively discussed in a recent review by Homeyer et al., ${ }^{36}$ which also underlined its huge potential in predicting relative binding energies in the biomolecular complexes. ${ }^{36}$ In this context, even more importantly than absolute values, the difference between the calculated $\Delta G_{\text {BIND }}$ is $3.5 \mathrm{kcal} \mathrm{mol}^{-1}$ in favor of SEL. To put this number in a proper 
perspective, let us mention that, although $K_{\mathrm{i}}$ and $\mathrm{IC}_{50}$ for irreversible inhibitors are not solely mirroring the binding of the inhibitors alone, they give useful insight into relative binding trends. As such, it is gratifying to see

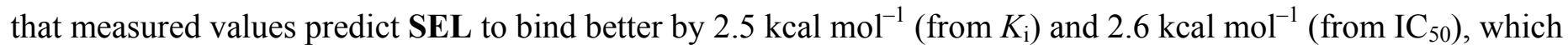
puts our results in a rather good agreement with experiments and lends credence to the presented conclusions.

Table 1. Calculated binding free energies $\left(\Delta G_{\mathrm{BIND}}\right)$ from molecular dynamics trajectories using MM-GBSA approach, and their decomposition on a per-residue basis (in $\mathrm{kcal} \mathrm{mol}^{-1}$ ). ${ }^{\mathrm{a}}$ Graphical representation is given in Figure S1. The obtained values are compared with available experiments.

\begin{tabular}{|c|c|c|}
\hline inhibitor & RAS & SEL \\
\hline$\Delta G_{\text {BIND }}$ & -28.36 & -31.83 \\
\hline FAD & -2.94 & -3.26 \\
\hline $\mathrm{Gln} 206$ & -2.53 & -2.59 \\
\hline Tyr435 & -0.87 & -1.39 \\
\hline Tyr398 & -1.73 & -1.25 \\
\hline Leu171 & -0.56 & -0.91 \\
\hline Tyr60 & -0.71 & -0.60 \\
\hline Cys 172 & -0.18 & -0.52 \\
\hline Phe343 & -0.82 & -0.51 \\
\hline Ile198 & -0.05 & -0.51 \\
\hline Gly434 & -0.15 & -0.38 \\
\hline Leu328 & -0.41 & -0.35 \\
\hline Tyr326 & -0.55 & -0.32 \\
\hline Thr399 & -0.07 & -0.21 \\
\hline Val173 & -0.04 & -0.18 \\
\hline Gly205 & -0.09 & -0.18 \\
\hline Met341 & -0.14 & -0.16 \\
\hline Gln 191 & -0.04 & -0.13 \\
\hline Arg42 & -0.01 & -0.11 \\
\hline Tyr188 & -0.03 & -0.11 \\
\hline Ile199 & -0.94 & -0.10 \\
\hline Ser59 & -0.10 & -0.10 \\
\hline$K_{\mathrm{i}}(\mathrm{h}-\mathrm{MAO}$ B) & $700 \mathrm{nM}^{\mathrm{b}}$ & $9 \mathrm{nM}^{\mathrm{c}}$ \\
\hline$I_{50}(h-M A O B)$ & $82.5 \mathrm{nM}^{\mathrm{d}}$ & $1.3 \mathrm{nM}^{\mathrm{e}}$ \\
\hline
\end{tabular}

${ }^{a}$ Residues are selected to list all of those with contributions higher than $-0.10 \mathrm{kcal} \mathrm{mol}^{-1}$ for $\mathbf{S E L}$ and these account for around half of the total binding for both inhibitors. A broader analysis in presented as Table S1 in the Supporting Information. ${ }^{b}$ From ref. $37 .{ }^{c}$ From ref. $38 .{ }^{d}$ From ref. 39. ${ }^{e}$ From ref. 40. 
Further analysis of MD trajectories and the decomposition of $\Delta G_{\mathrm{BIND}}$ values into contributions from specific residues provide some clues to why SEL binds better. Table 1 shows that both inhibitors are primarily stabilized by interacting with FAD, which accounts for around 10\% of the total binding energies. This is established through favorable $\pi \cdots \pi$ interactions among the aromatic rings on FAD and inhibitors acetylene groups, which are mainly responsible for positioning inhibitors in reactive conformations. Interestingly, with its acidic $\mathrm{N}-\mathrm{H}$ group, RAS forms hydrogen bonding with the carbonyl $\mathrm{C}(4)=\mathrm{O}$ group on FAD. This is persistent through the entire MD simulation (Figure S2) with the average N(RAS)-O(FAD) distance of $3.427 \AA$, yet the overall interaction with FAD is lower. In SEL, this position is $N$-methylated, which then prevents hydrogen bonding with the co-factor and results in its farther distance from FAD in the enzyme-inhibitor complex (Figure S3). Yet, it will turn out (see later) that this RAS-FAD hydrogen bonding, in addition to lowering the binding, exerts a negative effect on the reactivity as well. Furthermore, RAS can act both as a donor and acceptor of the hydrogen bonding with active site residues, which permit it to interact with, for example, the $-\mathrm{OH}$ groups in tyrosines. On the other hand, SEL can only act as a hydrogen bond acceptor, yet even this ability is sterically hindered with the present $N$-methyl group. As a result, RAS forms hydrogen bonds around four times more frequently than SEL (0.8 vs. 0.2 hydrogen bonds per each ns of the MD simulation, respectively, Figure S4), yet its overall binding is lower. This strongly underlines that the capacity of inhibitors to form hydrogen bonds within the active site is not primarily responsible for the affinity, but other electrostatic and hydrophobic interactions are dominating in this respect. Therefore, our results indicate that, for a successful design of novel inhibitors, it is likely beneficial to have a tertiary instead of a secondary amino group within the structure.
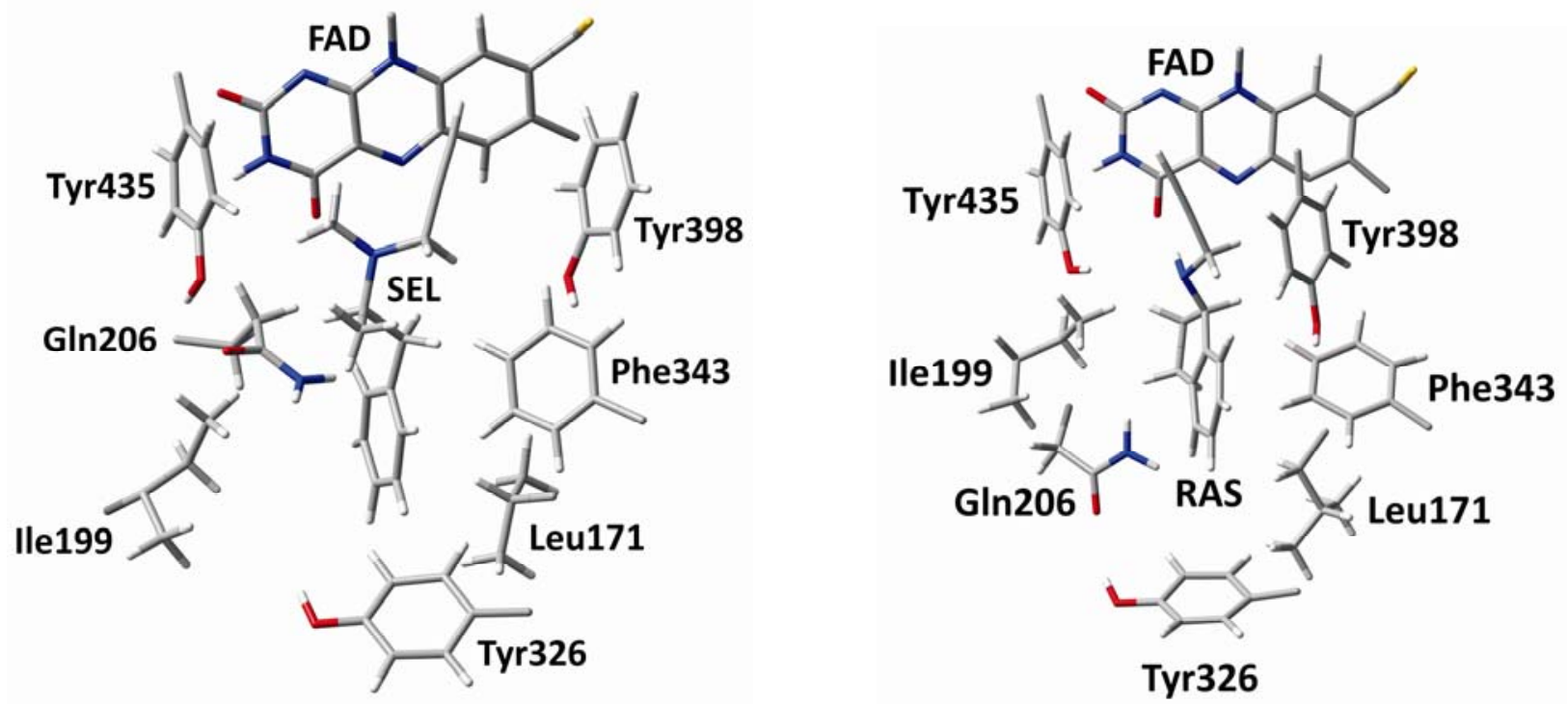

Figure 2. Representative structures of irreversible inhibitors selegiline (SEL, left) and rasagiline (RAS, right) placed within the MAO B active site as obtained from the MD simulations. 
Interestingly, among amino acid residues, both inhibitors are mostly stabilized by Gln206 achieved by its side chain $-\mathrm{NH}_{2}$ group interacting with aromatic fragments on inhibitors through favorable $\mathrm{N}-\mathrm{H} \cdots \pi$ interactions (Figure S5). This fact emphasizes the significance of aromatic moieties in the design of more potent compounds, which promote the binding within the hydrophobic active site. ${ }^{41}$ Tyrosines Tyr435 and Tyr398 were identified both experimentally ${ }^{42}$ and computationally ${ }^{41,43}$ as important in properly orienting substrates for the chemical reaction, and their mutations have led to enzymes with considerably reduced activities. ${ }^{44}$ Analogously, it turned out that these residues are also significant for the inhibitor affinity (Figure 2), together with other active site tyrosines, Tyr60 and Tyr326 (Figure S6), and one phenylalanine residue Phe343. Unlike hydrogen bonding, SEL is more efficient in interacting with aromatic residues, as evidenced in its higher propensity to interact with four active site tyrosines (Figure S6), by making around 0.50 such contacts per each ns of the MD simulation, as opposed to 0.34 contacts that RAS forms. This is strongly in line with Geha et al., ${ }^{45}$ who demonstrated that $\mathrm{IC}_{50}$ for SEL is increased 15 and 130 times upon Tyr398Phe and Tyr435Phe mutations. In addition, SEL is clearly a more flexible molecule, with more rotatable bonds, allowing it to assume such conformations to optimize contacts with other hydrophobic residues as well, such as Leu171, Cys172 and Gly434. Lastly, what is particularly interesting are inhibitors' interactions with Ile199, since this residue was experimentally proposed as the "gating residue" in MAO B, ${ }^{46}$ supported by recent calculations, ${ }^{43}$ in some studies together with Tyr326. ${ }^{47}$ Notably, Ile199 is conserved in all known MAO B sequences except bovine MAO B, which has Phe in this position that is, in turn, a conserved residue in the analogous position in MAO A. It is demonstrated that in a "closed conformation", Ile199 separates hydrophobic entrance and substrate cavities in MAO B thus producing a bipartite active site configuration, while its "open conformation" allows the fusion of both cavities to a large total volume of $\sim 700 \AA^{3}$, much larger than a monopartite substrate cavity of $\sim 550 \AA^{3}$ in MAO A, and a successful substrate or inhibitor binding. ${ }^{46}$ Since SEL is larger and more elongated than RAS, it pushes both Ile199 and Tyr326 to adopt an "open conformation", which creates a cavity big enough to accommodate SEL and diminishes their interactions (Table 1), as already observed in all human MAO B crystal structures in complex with bulky inhibitors. ${ }^{24 b}$ Still, this change within the enzyme enhances the overall binding of SEL, which now includes interactions with residues from both cavities, matching observations that MAO B displays an increase in the binding affinity for systems that bridge both cavities. ${ }^{47}$ On the other hand, RAS is a more compact molecule than SEL and smaller conformational changes in the cavities are required for its binding, which promotes its interactions with both Ile199 and Tyr326, being as large as -0.94 and $-0.55 \mathrm{kcal} \mathrm{mol}^{-1}$, respectively. This is fully in line with crystallographic analysis revealing that RAS snugly fits into the substrate cavity alone, and that Ile199 is in contact with its benzene moiety. ${ }^{48}$ This notion is also strongly supported by the fact that for a very small inhibitor isatin, the $K_{\mathrm{i}}$ value is increased four times upon Ile199Ala mutation and more than 100-fold in the Ile199AlaTyr326Ala double MAO B mutant. ${ }^{47}$ Taken all together, these results further underline a critical role of Ile199 
and Tyr326 in determining inhibitor binding specificity for MAO B, and strongly indicate that aromatic and hydrophobic interactions are promoting the binding.

In summarizing this section, the obtained results confirm that SEL is a better binder primarily because it is a more flexible molecule being able to adjust its hydrophobic interactions with active site residues throughout both cavities, thus overcoming a better propensity of RAS to both accept and donate hydrogen bonds. As the calculated relative binding energies and found in very good agreement with experiments, this insight provides the first step in designing more effective MAO B inhibitors.

Quantum Chemical Analysis of the Inhibition Reaction. Although the initial discovery of mammalian MAOs was published 90 years ago, ${ }^{49,50}$ and despite the fact that their inhibitors, reversible and irreversible, equipotent on both isoforms or highly selective, have been used for more than 60 years for the treatment of various neurological disturbances, ${ }^{12}$ the precise molecular mechanism by which irreversible inhibitors form the N5 adduct with FAD and, thereby, suppress MAO's further catalytic activity has remained unknown. A possible reason for that becomes evident by looking at the adduct structure (Figure 1). Namely, apart from creating a chemical bond with N5(FAD), the inhibitor must undergo a 1,2-hydrogen shift from $C(\alpha)$ to $C(\beta)$ to allow the final product. This suggests this is not a simple reaction and it certainly involves more than one step. To address this question, following MD simulations, we created a cluster model of MAO B with both RAS and SEL, including the FAD co-factor and Tyr435, Tyr398, Tyr326, Tyr188, Ile199, Lys296, Cys172 and Gln206 residues, together with three active site water molecules, as described in the Supporting Information. M06-2X/6-31+G(d,p) geometry optimization gave stationary points corresponding to enzyme-inhibitor complexes (Figure 2).

Initially, we first tried to model a direct $\mathrm{C}(\gamma)_{\text {inhibitor }}$-N5(FAD) bond forming reaction starting with neutral inactivated inhibitors. This reaction probes the electrophilic character of the co-factor's N5 atom and its propensity to attack the inhibitor $\pi$-system. Taking SEL as an example, with unionized Lys 296 the reaction is favorable $\left(\Delta G_{\mathrm{r}}=-19.8 \mathrm{kcal} \mathrm{mol}^{-1}\right)$ and the formed adduct is stable and characterized with the $\mathrm{C}(\gamma)-\mathrm{N} 5$ distance of $1.430 \AA$. However, this reaction is associated with a very high barrier of $47.8 \mathrm{kcal} \mathrm{mol}^{-1}$, which makes it unlikely. In the case of a monoprotonated Lys296, the reaction becomes even endergonic $\left(\Delta G_{\mathrm{r}}=4.9 \mathrm{kcal} \mathrm{mol}^{-1}\right)$ while maintaining the barrier height. A similar magnitude of values is obtained with RAS as well. All of this suggests that the inhibition process does not follow this mechanism.

Secondly, we assumed that inhibitors get activated by terminal $\mathrm{C}(\gamma)-\mathrm{H}$ deprotonation. In the absence of basic active-site residues to perform the proton abstraction, ${ }^{51}$ we modeled a direct inhibitor deprotonation by N1 on FAD (Figure 1). This was prompted by the vicinity of these two centers (5.505 $\AA$ for SEL, and $3.327 \AA$ for RAS), 
and the fact that N1 is the most basic position on FAD. ${ }^{52}$ This is further supported by the NBO charges on N1, $0.64|\mathrm{e}|$ for both inhibitors in the reactants. Yet, the obtained products, the N1-protonated FAD and a deprotonated inhibitor are much less stable than initial systems, having $\Delta G_{\mathrm{r}}=30.6 \mathrm{kcal} \mathrm{mol}^{-1}$ for SEL with unionized Lys296 and $\Delta G_{\mathrm{r}}=23.0 \mathrm{kcal} \mathrm{mol}^{-1}$ with ionized Lys296. Such high energy requirements are rationalized by a large difference in the $\mathrm{p} K_{\mathrm{a}}$ values between proton donor and acceptor sites. For the flavin N1-H deprotonation this was measured to be around $7.0,{ }^{53}$ whereas acetylene deprotonation typically has a $\mathrm{p} K_{\mathrm{a}}$ of around $25,{ }^{54}$ and can be achieved only by very strong superbases. ${ }^{54}$

Recently, we performed the first QM study that demonstrated the prevailing feasibility of the direct hydride transfer mechanism over several alternative pathways for the catalytic dopamine degradation using a similar cluster model of MAO B. ${ }^{52}$ This was later extended by considering the full enzyme dimensionality through the empirical valence bond QM/MM approach, ${ }^{55}$ which gave the activation free energy of $16.1 \mathrm{kcal} \mathrm{mol}^{-1}$, being in excellent agreement with the experimentally determined value of $16.5 \mathrm{kcal} \mathrm{mol}^{-1}{ }^{24 \mathrm{~b}}$ thus supporting the proposed mechanism. Latter, we expanded our work to a range of other substrates and MAO A isoform as well, ${ }^{43,56}$ and all of the results agree well with experiments employing the mechanism in which the hydride anion is transferred from the substrate's C( $\alpha$ ) atom to N5(FAD) in the rate-limiting first step. Our mechanistic picture is gaining some affirmation in the literature, ${ }^{57}$ and is fully corroborated by very recent ${ }^{13} \mathrm{C}$ kinetic isotope effect measurements on a related polyamine oxidase flavoenzyme. ${ }^{58}$ For those reasons, we deemed it worthwhile to employ this mechanism in understanding the inhibition reaction, particularly since it is established that both RAS and SEL are mechanism-based irreversible inhibitors. ${ }^{9,20}$

Optimization of initial geometries gave stationary points (SP1, Figure 3) where both inhibitors are properly oriented for the hydride abstraction. As already discussed, because of its acidic N-H group, RAS is positioned closer to FAD, contrary to SEL that features the $N$-methyl moiety which prevents a shorter proximity. In SP1, the corresponding N5(FAD)-C( $\alpha$ ) distances are $3.523 \AA$ for RAS and $4.386 \AA$ for SEL. These are found in excellent agreement with average values of 3.669 and $4.223 \AA$ obtained after MD simulations (Figure S3), which strongly supports the selection of representative MD snapshots for the subsequent quantum-mechanical analysis. 


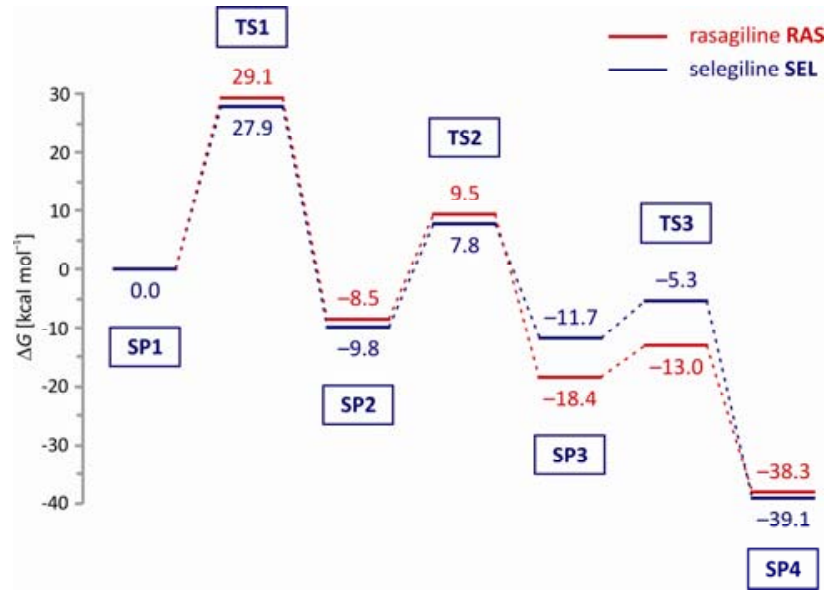

Figure 3. Free-energy profiles for the irreversible MAO B inhibition with rasagiline (RAS) and selegiline (SEL). Initial rate-limiting step involves a direct hydride anion transfer from the methylene $C(\alpha)$ atom onto the N5 atom of the FAD co-factor. Acronyms SP and TS indicate stationary points and transition states, respectively, and their chemical structures are depicted in Figure 4.

Direct $\alpha$-hydride abstraction turned out feasible in both inhibitors (Figure 3), in agreement with our results for the MAO catalysis. ${ }^{43,52,55,56}$ In the transition state TS1, the transferring hydrogen is placed between the leaving $\alpha-$ carbon and the accepting N5 atom, with the bond distances of 1.408 and $1.268 \AA$ for RAS, respectively, being somewhat more symmetrical in SEL at 1.410 and 1.280 $\AA$, in the same order. Despite these similarities, the activation free energy for this process in SEL is $27.9 \mathrm{kcal} \mathrm{mol}^{-1}\left(v_{\text {imag }}=1243 i \mathrm{~cm}^{-1}\right)$, which is increased to 29.1 $\mathrm{kcal} \mathrm{mol}^{-1}$ in $\mathbf{R A S}\left(v_{\text {imag }}=1213 i \mathrm{~cm}^{-1}\right)$. Since this is the rate-limiting step of the overall transformation (Figure 3 ), these values deserve some further comments. Interestingly, this trend in the reactivity, which predicts SEL to react more efficiently, is fully in line with the determined $k_{\text {inact }}$ values of $0.99 \mathrm{~min}^{-1}$ for $\mathbf{S E L} \mathbf{L}^{59}$ and $0.0533 \mathrm{~min}^{-1}$ for RAS. ${ }^{60}$ Even more so, these experimental parameters translate to a difference in the activation free energy of $1.7 \mathrm{kcal} \mathrm{mol}^{-1}$ in favor of SEL, which is excellently matched by our calculations of $1.2 \mathrm{kcal} \mathrm{mol}^{-1}$ here (Figure 3) that lends strong credence to our results.

A possible explanation for a lower reactivity of RAS is offered by considering geometric parameters within the active site. Namely, in addition to its lower flexibility, the hydrogen bonding that RAS makes with both FAD and neighboring residues locks it in a position in which it is less prepared for the $\mathrm{H}^{-}$abstraction. Specifically, the distribution of relevant angles N5(FAD) $\cdots \mathrm{H}-\mathrm{C}(\alpha)$ for both methylene hydrogens in SEL is such that there is always one $\mathrm{H}$-atom with the angle close to $0^{\circ}$ (Figure S7) that is optimal for the $\mathrm{H}^{-}$transfer. In this way SEL is able to more successfully optimize its position for the reaction with FAD. In contrast, RAS is more rigid and only one of its methylene hydrogens can undergo the hydride abstraction. Furthermore, through electron-donation, the 
additional amino $N$-methyl group in SEL provides extra stabilization to the positive charge created upon the $\mathrm{H}^{-}$ abstraction, an effect absent in RAS. To illustrate that, our calculations on isolated inhibitors show that it is by 7.6 $\mathrm{kcal} \mathrm{mol}^{-1}$ easier to strip $\mathrm{H}^{-}$from $\mathrm{C}(\alpha)$ in SEL than it is in RAS, a result dominated by the presence of the electron donating methyl group on the vicinal amino nitrogen.

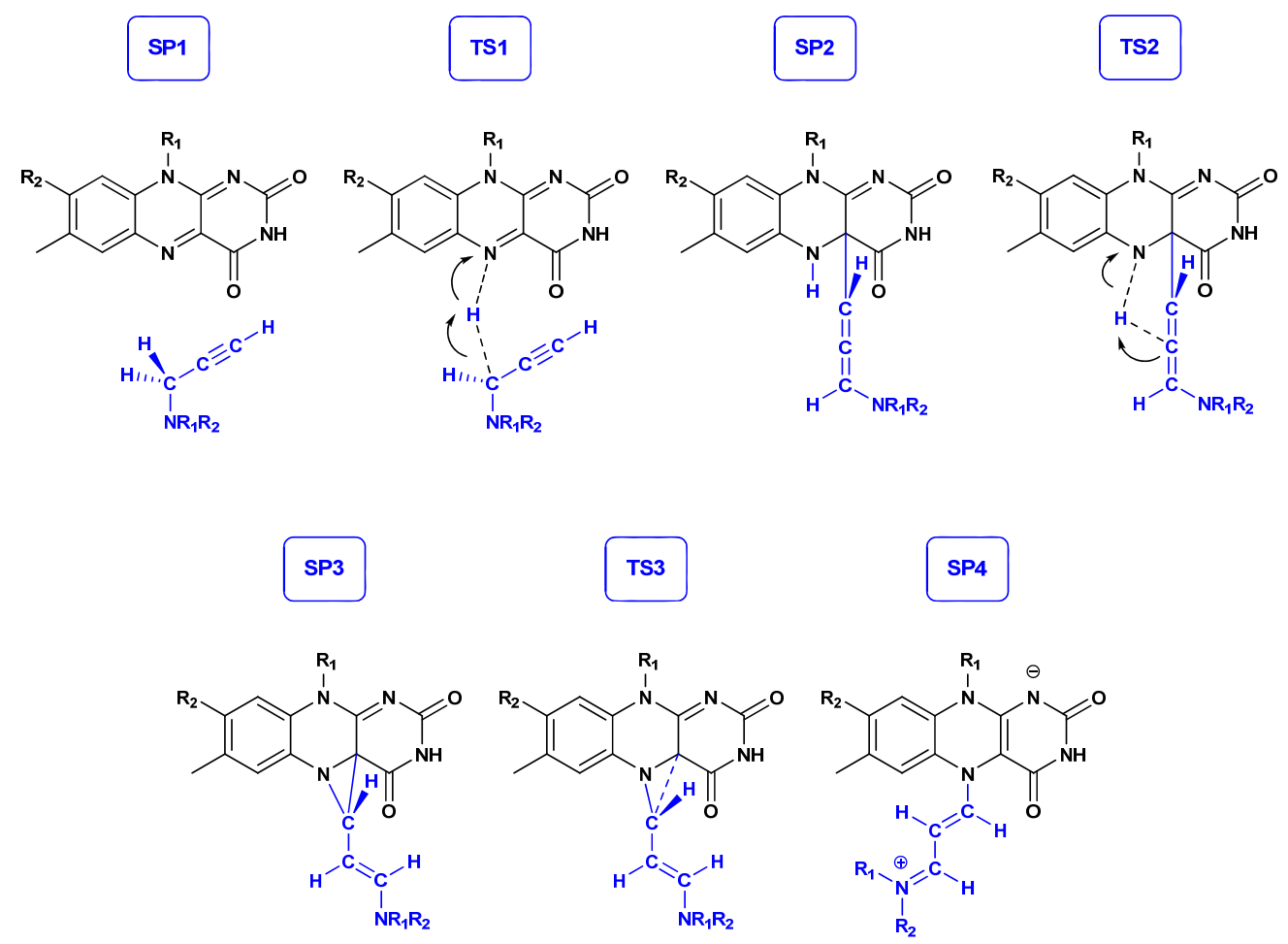

Figure 4. Chemical structures corresponding to stationary points (SP) and transition states (TS) during the irreversible MAO inhibition reaction in the most feasible hydride transfer mechanism, in accordance with free energy profiles shown in Figure 3.

The fact that this process is indeed associated with the transfer of a hydride anion is evident in the atomic NBO charges and relevant bond distances. Here, we are presenting results for SEL (Table 2), while the corresponding data for RAS are found in Table S2, being similar and offering same conclusions. Initially, total charges on SEL and FAD in SP1 are 0.01 and $0.03|\mathrm{e}|$, respectively, to be altered to 0.36 and $-0.36|\mathrm{e}|$ in TS1. This indicates that during the reaction SEL loses around one third of an electron that is afterwards accommodated on FAD. In addition, the charge on the accepting N5(FAD) changes from $-0.36|e|$ in SP1 to $-0.51|e|$ in TS1. Interestingly, the charge on the inhibitor $\mathrm{C}(\alpha)$ atom, from which the $\mathrm{H}^{-}$anion is abstracted, changes only moderately from 0.26 to $0.37|\mathrm{e}|$, which is rationalized by the presence of the neighboring amino group that compensates the charge loss 
through electron donation. This is seen in the reduced charge on the amino nitrogen and the shortened N(amino)$\mathrm{C}(\alpha)$ distance, changing from $-0.54|\mathrm{e}|$ and $1.473 \AA$ in SP1 to $-0.48|\mathrm{e}|$ and $1.409 \AA$ in TS1, which is all consistent with the proposed $\mathrm{H}^{-}$transfer.

Table 2. Charge distribution (NBO analysis, in $|\mathrm{e}|$ ) and selected bond distances (in $\AA$ ) during the rate-limiting hydride abstraction in the irreversible inhibition reaction with selegiline (SEL) as obtained at the (CPCM)/M06$2 \mathrm{X} / 6-31+\mathrm{G}(\mathrm{d}, \mathrm{p})$ level.

\begin{tabular}{|c|c|c|c|c|c|}
\hline System & $\begin{array}{l}\text { Atom/Bond/ } \\
\text { Molecule }\end{array}$ & Isolated & $\begin{array}{c}\text { Enzyme- } \\
\text { Inhibitor } \\
\text { Complex (SP1) }\end{array}$ & $\begin{array}{c}\text { Transition } \\
\text { State (TS1) }\end{array}$ & $\begin{array}{l}\text { Intermediate } \\
\text { (SP2) }\end{array}$ \\
\hline & $\mathrm{N}_{\text {amino }}$ & -0.52 & -0.54 & -0.48 & -0.50 \\
\hline & $\mathrm{C}\left(\mathrm{N}_{\text {amino }}\right)$ & -0.50 & -0.50 & -0.50 & -0.50 \\
\hline & $\alpha-H$ & 0.24 & 0.26 & 0.37 & 0.46 \\
\hline & $\alpha-\mathrm{C}$ & -0.34 & -0.35 & -0.24 & -0.04 \\
\hline & $\beta-C$ & -0.04 & -0.03 & -0.04 & -0.06 \\
\hline & $\gamma-\mathrm{C}$ & -0.25 & -0.27 & -0.27 & -0.31 \\
\hline & SEL & 0.00 & 0.01 & 0.36 & 0.51 \\
\hline & $\mathrm{N}-\mathrm{C}$ (methyl) & 1.462 & 1.467 & 1.464 & 1.464 \\
\hline & $\mathrm{N}-\mathrm{C}(\alpha)$ & 1.466 & 1.473 & 1.409 & 1.395 \\
\hline & $C(\alpha)-C(\beta)$ & 1.469 & 1.468 & 1.403 & 1.320 \\
\hline & $C(\beta)-C(\gamma)$ & 1.205 & 1.207 & 1.234 & 1.307 \\
\hline & N5 & -0.34 & -0.36 & -0.51 & -0.68 \\
\hline & $\mathrm{C} 4 \mathrm{a}$ & 0.09 & 0.10 & 0.05 & -0.01 \\
\hline & $\mathrm{C} 10 \mathrm{a}$ & 0.45 & 0.45 & 0.48 & 0.54 \\
\hline & N1 & -0.65 & -0.64 & -0.65 & -0.65 \\
\hline & FAD & 0.00 & 0.03 & -0.36 & -0.54 \\
\hline & $\mathrm{N}(5)-\mathrm{C}(4 \mathrm{a})$ & 1.291 & 1.290 & 1.336 & 1.434 \\
\hline & $C(4 a)-C(10 a)$ & 1.461 & 1.458 & 1.455 & 1.515 \\
\hline & $\mathrm{C}(10 \mathrm{a})-\mathrm{N}(1)$ & 1.307 & 1.306 & 1.310 & 1.302 \\
\hline
\end{tabular}

Initial hydride transfer is exergonic, $\Delta G_{\mathrm{r}}=-9.8 \mathrm{kcal} \mathrm{mol}^{-1}$ for SEL and $\Delta G_{\mathrm{r}}=-8.5 \mathrm{kcal} \mathrm{mol}^{-1}$ for RAS, and creates a negatively charged $\mathbf{F A D H}{ }^{-}$and a positively charged inhibitor. This is shown in the charge distribution, as the full formation of a new N5- $\mathrm{H}^{-}$bond increases the charge on FAD to $-0.54|\mathrm{e}|$, while the charge on SEL becomes $0.51|\mathrm{e}|$. Such electrostatic difference leads to a spontaneous adduct formation SP2 (Figure 4), where the 
inhibitor $\mathrm{C}(\gamma)$ atom binds to $\mathrm{C} 4 \mathrm{a}$ on FAD. The formed adduct is rather strong, as evidenced in short $\mathrm{C}(\gamma)-\mathrm{C} 4 \mathrm{a}$ bonds of $1.555 \AA$ for SEL and $1.545 \AA$ for RAS. Moreover, the calculated adduct dissociation energies are $\Delta G_{\text {diss }}$ $=31.1 \mathrm{kcal} \mathrm{mol}^{-1}$ for SEL and $\Delta G_{\text {diss }}=36.3 \mathrm{kcal} \mathrm{mol}^{-1}$ for $\mathbf{R A S}$, which confirm their strong nature. Yet, despite their stability, the reaction proceeds further as the following stationary points are found even lower in energy than SP2. Binding to FAD creates an allene-type motif within inhibitors (SP2, Figure 4) as evidenced in an even distribution of $\mathrm{C}(\alpha)-\mathrm{C}(\beta)$ and $\mathrm{C}(\beta)-\mathrm{C}(\gamma)$ bonds of 1.320 and $1.307 \AA$ in SEL, and 1.315 and $1.306 \AA$ in RAS. In allene, the most reactive/nucleophilic is the middle $\mathrm{C}(\beta)$ atom, ${ }^{61}$ so the next step involves the transfer of the abstracted hydrogen from N5(FAD) onto $\mathrm{C}(\beta)$ as a proton $\mathrm{H}^{+}$, as seen in the charge within SEL that changes from $0.51|\mathrm{e}|$ in SP2 to $0.73 \mathrm{e} \mid$ in TS2. An analogous transfer to $\mathrm{C}(\gamma)$ is not feasible, while that to $\mathrm{C}(\alpha)$ reverts the system back to SP1. The mentioned $\mathrm{N} 5-\mathrm{H} \cdots \mathrm{C}(\beta)$ proton transfer is associated with barriers of $17.6 \mathrm{kcal}^{-1} \mathrm{~mol}^{-1}$ for SEL $\left(v_{\text {imag }}=1075 i \mathrm{~cm}^{-1}\right)$ and $18.0 \mathrm{kcal} \mathrm{mol}^{-1}$ for $\operatorname{RAS}\left(v_{\text {imag }}=1283 i \mathrm{~cm}^{-1}\right)$, which are smaller than those for the initial $\mathrm{H}^{-}$abstraction. This creates SP3, which features the formation of a strained three-membered ring among N5 and C4a on FAD and C $(\gamma)$ on an inhibitor (Figure 4), yet it is further lower in energy, likely because of the instability of the allene structure in the confined environment of the preceding SP2. The corresponding N5-C( $\gamma)$, N5-C4a and $\mathrm{C} 4 \mathrm{a}-\mathrm{C}(\gamma)$ distances are $1.465,1.452$ and $1.537 \AA$ for SEL, while 1.468, 1.454 and $1.530 \AA \AA$ for RAS, respectively. Although strained, SP3 is more stable than SP2, likely due to the instability of an allene in this confined environment. Interestingly, the reaction leading to SP3 is more exergonic for RAS, although it will turn out that the overall thermodynamic profile is more favorable for SEL (Figure 3).

The last step involves the breaking of the bond between $\mathrm{C}(\gamma)_{\text {inhibitor }}-\mathrm{C} 4 \mathrm{a}($ FAD $)$ and the formation of a full C $(\gamma)-N 5($ FAD) bond as in SP4. In TS3, the former are already much elongated to $1.929 \AA$ (SEL) and $1.820 \AA$ (RAS), while the process is linked with barriers of $6.4 \mathrm{kcal} \mathrm{mol}^{-1}$ for SEL $\left(v_{\text {imag }}=305 i \mathrm{~cm}^{-1}\right)$ and $5.4 \mathrm{kcal} \mathrm{mol}^{-1}$ for RAS $\left(v_{\text {imag }}=383 i \mathrm{~cm}^{-1}\right)$, being the smallest along the profile. This step is highly exergonic and leads to final products. Specifically, in RAS the end product is stabilized by $25.3 \mathrm{kcal} \mathrm{mol}^{-1}$ to a final $\Delta G_{\mathrm{r}}=-38.3 \mathrm{kcal} \mathrm{mol}^{-1}$. This is even more pronounced in SEL, which benefits from $33.8 \mathrm{kcal} \mathrm{mol}^{-1}$ stabilization to give $\Delta G_{\mathrm{r}}=-39.1 \mathrm{kcal}$ $\mathrm{mol}^{-1}$. The electronic structure of adduct is complex, and it involves a positive charge delocalized within the conjugated inhibitor cyanine chain. Most of the excess positive charge is located within the $\mathrm{N}($ amino) and $\mathrm{C}(\alpha)$ atoms that gain 0.18 and $0.49|\mathrm{e}|$ relative to SP1, while the bond connecting these two atoms is shortened by 0.05 $\AA$ (Table 3). The conjugated scaffold was also confirmed by a very recent computational analysis of a hindered rotation about both pairs of $\mathrm{C}-\mathrm{N}$ and $\mathrm{C}-\mathrm{C}$ bonds within a model system. ${ }^{62}$ Moreover, the geometry of the final adduct is in very good agreement with available X-ray structures (Table 3). Interestingly, in SP4, FAD features an anionic $\mathrm{N} 1$ atom with the NBO charge of $-0.67|\mathrm{e}|$, being consistent with very recent mass spectrometry data that revealed a deprotonated nature of the $\mathrm{N} 1$ site in the adduct even under fairly acidic experimental conditions $(\mathrm{pH} \approx$ 2). ${ }^{62}$ 
Table 3. Charge distribution (in $|e|)$ and selected bond distances (in $\AA$ ) in the N5(FAD) adducts with selegiline and rasagiline. Comparison is done with available crystal structures.

\begin{tabular}{|c|c|c|c|c|c|}
\hline Structure & Bond/Atom & Selegiline Adduct & 2BYB.pdb & Rasagiline Adduct & 1S2Q.pdb \\
\hline \multirow{14}{*}{$\begin{array}{l}\text { Enzyme } \\
1 \\
c\end{array}$} & $\mathrm{~N} 5-\mathrm{C}(\gamma)$ & 1.329 & 1.28 & 1.331 & 1.28 \\
\hline & $\mathrm{C}(\gamma)-\mathrm{C}(\beta)$ & 1.387 & 1.33 & 1.383 & 1.29 \\
\hline & $C(\beta)-C(\alpha)$ & 1.398 & 1.52 & 1.394 & 1.53 \\
\hline & $\mathrm{C}(\alpha)-\mathrm{N}($ amino $)$ & 1.315 & 1.47 & 1.311 & 1.29 \\
\hline & N5-C4a & 1.420 & 1.39 & 1.419 & 1.38 \\
\hline & $\mathrm{C} 4 \mathrm{a}-\mathrm{C} 10 \mathrm{a}$ & 1.404 & 1.41 & 1.398 & 1.39 \\
\hline & $\mathrm{C} 10 \mathrm{a}-\mathrm{N} 1$ & 1.326 & 1.38 & 1.332 & 1.39 \\
\hline & N5 & -0.36 & & -0.36 & \\
\hline & $\mathrm{C}(\gamma)$ & 0.14 & & 0.13 & \\
\hline & $C(\beta)$ & -0.48 & & -0.44 & \\
\hline & $C(\alpha)$ & 0.15 & & 0.15 & \\
\hline & N(amino) & -0.37 & & -0.56 & \\
\hline & $\mathrm{C} 4 \mathrm{a}$ & -0.14 & & -0.14 & \\
\hline & $\mathrm{C} 10 \mathrm{a}$ & 0.47 & & 0.46 & \\
\hline & N1 & -0.67 & & -0.71 & \\
\hline
\end{tabular}

In finishing this section, it is worth to emphasize that the revealed mechanism is feasible as it proceeds downhill in energy with high exergonicity of the overall transformation and the rate-limiting hydride abstraction. It also confirms experimental observations that both SEL and RAS are mechanism-based irreversible inhibitors, ${ }^{9,20}$ while the obtained free-energy profiles rationalize the higher reactivity of SEL from both the lower activation free-energy $\Delta \Delta G^{\ddagger}=1.2 \mathrm{kcal} \mathrm{mol}^{-1}$ and a more pronounced exergonicity $\Delta \Delta G_{\mathrm{r}}=0.8 \mathrm{kcal} \mathrm{mol}^{-1}$. To further strengthen our conclusion, let us mention that we excluded the possibility of the electron-transfer mechanism, in which an inhibitor is activated by transferring an electron to FAD, a process that was considered for the MAO catalysis. ${ }^{63}$ Our model gave the following ionization free energies, $\operatorname{IE}(\mathbf{S E L})=134.5 \mathrm{kcal} \mathrm{mol}^{-1}$ and $I E(\mathbf{R A S})=146.1 \mathrm{kcal} \mathrm{mol}^{-1}$, which are not matched by the calculated electron affinity $E A(\mathbf{F A D})=-77.2 \mathrm{kcal}$ $\mathrm{mol}^{-1}$. Such a large energy mismatch suggests electron transfer to FAD is highly implausible and we did not consider it further. In addition, the calculated free-energy profiles involving the ionized active-site Lys296 residue (Figure S8) show investigated reactions are less favorable than those already presented for the neutral Lys296. In this way, these results parallel those we obtained for the MAO catalytic activity, where the MAO B dopamine degradation proceeds with unionized Lys $296,{ }^{55}$ and confirm it is very likely this residue has an active role only in 
activating the molecular oxygen and facilitating the regeneration of $\mathbf{F A D H} \mathbf{H}_{\mathbf{2}}$ to $\mathbf{F A D}$, and not in the catalytic transformation of substrates or in the inhibition reaction, as already speculated in the literature. ${ }^{64}$

\section{CONCLUSIONS}

While there have been no revolutionary treatments for Parkinson and Alzheimer diseases in the last few decades, great interest remains in the development of new drugs, novel delivery systems, and drug combinations, which are of utmost importance with the growing prevalence of these illnesses. MAO B inhibitors are widely used in the management of both diseases and a variety of other psychiatric disorders, and continue to be investigated for their therapeutic value and disease-modifying potential.

Here we used a combination of MD simulations, MM-GBSA binding free energy evaluations, and QM cluster calculations to elucidate the precise molecular mechanism behind the irreversible MAO inhibition with propargylamine drugs, and rationalize higher reactivity of selegiline (SEL) over rasagiline (RAS) that are both in the clinical use. We showed the MAO inactivation proceeds through a three-step reaction, where, in the ratelimiting first step, the enzyme uses the N5 atom on its FAD co-factor to abstract a hydride anion from the inhibitor's $\alpha-\mathrm{CH}_{2}$ group, being in full analogy with the MAO catalytic mechanism, thus confirming both SEL and RAS are mechanism-based inhibitors. The initial hydride abstraction creates a C4a(FAD) adduct and an allenemotif in the inhibitor, which proceeds by transferring the N5-hydrogen back to the inhibitor's $C(\beta)$ atom, which then forms a three-membered ring with $\mathrm{C}(\gamma)$, and N5 and C4a atoms on FAD. The last step involves the breaking of a bond with the $\mathrm{C} 4 \mathrm{a}$ atom and the formation of the $\mathrm{N} 5$-adduct, thus nicely tying in with the crystallographic structures. The obtained reaction profiles reveal that the overall process is both kinetically and thermodynamically more favorable for $\mathbf{S E L}$, as its activation energy is lower by $\Delta \Delta G^{\ddagger}=1.2 \mathrm{kcal} \mathrm{mol}^{-1}$ and the reaction is more exergonic by $\Delta \Delta G_{\mathrm{r}}=0.8 \mathrm{kcal} \mathrm{mol}^{-1}$. Both of these support the fact $\mathbf{S E L}$ is a more potent inhibitor as evidenced in the measured $k_{\text {inact }}$ values, which predicts a difference of $\Delta \Delta G^{\ddagger}$ EXP $=1.7 \mathrm{kcal} \mathrm{mol}^{-1}$, hence putting our results in excellent agreement with experiments. Let us also mention that it remains a challenge to experimentally confirm the anionic nature of the inhibitor-FAD transferring hydrogen during the inhibition. As possible routes to achieve that, one could turn to structure-relation studies with a series of modified compounds, or utilize kinetic measurements with isotopically labeled inhibitors, ${ }^{58}$ and their realization is strongly recommended. In addition, we hope these results will also stimulate further computational efforts that should, among other things, evaluate the influence of the whole enzyme environment and potential mutations on the inhibition reaction. Although our extensive experience with QM cluster calculations suggests this is unlikely to change the presented mechanistic conclusions, ${ }^{41,43,52,55,56}$ this is a welcome task, since a very recent report ${ }^{65}$ underlined the importance of residues 
beyond the immediate vicinity of the active site in determining the catalytic power of the MAO A isoform, and signified the likely decisive role of electrostatics in the enzymatic reactions.

The higher reactivity of SEL is further promoted by several contributions. SEL is larger and a more flexible molecule, so it assumes elongated active-site conformations that allow it to stretch and maximize interactions with residues from both MAO cavities, yielding a higher $\Delta G_{\mathrm{BIND}}(\mathbf{S E L})=-31.83 \mathrm{kcal} \mathrm{mol}^{-1}$. In contrast, $\mathbf{R A S}$ is a more rigid and compact system binding only within a substrate cavity closer to FAD. This leads to more pronounced interactions with the "gating" Ile199 and Tyr326 residues, yet the overall binding is lower at $\Delta G_{\mathrm{BIND}}(\mathbf{R A S})=-28.36 \mathrm{kcal} \mathrm{mol}^{-1}$, being in line with measured $K_{\mathrm{i}}$ and $\mathrm{IC}_{50}$ data. In addition, RAS has a secondary amine $\mathrm{N}-\mathrm{H}$ group that can both donate and accept hydrogen bonds, which is not the case with SEL that features an $\mathrm{N}$-methyl group. Indeed, our results revealed RAS is around four times more frequent in forming hydrogen bonds within the active site, yet these only position it in less reactive orientations for the subsequent $\mathrm{H}^{-}$ abstraction. What is responsible for better binding of SEL are hydrophobic $\mathrm{C}-\mathrm{H} \cdots \pi$ and $\pi \cdots \pi$ interactions, particularly with four active site tyrosines and FAD, and favorable $\mathrm{N}-\mathrm{H} \cdots \pi$ interactions with Gln206 that was identified as the most dominant residue in the SEL binding.

Taken all together, the computational insight presented here suggests that, for a future design of more potent irreversible MAO inhibitors, one should look for long flexible molecules with aromatic fragments or other moieties rich in $\pi$-electrons, which would be able to stretch and optimize hydrophobic interactions with residues within both of enzymes cavities. Also, tertiary amines are more likely to assume reactive conformations than secondary analogues, while additionally providing a stabilizing electron-donating effect with its $N$-alkyl group during the rate-limiting $\mathrm{H}^{-}$abstraction reaction. Also, given the residual ${ }^{1-3}$ and electrostatic ${ }^{66}$ similarities in their active sites and overall structures, this insight could turn beneficial for the design of MAO A inhibitors as well, that are clinically employed to treat various forms of depression. ${ }^{12}$

The increase of MAO B activity in ageing brain resulting in increased oxidative stress suggests that the hunt for new effective brain-targeted MAO B inhibitors will continue. Although new reversible inhibitors have been proposed, there is no indication that they will be successful in vivo. By being the first to demonstrate the prevailing feasibility of the hydride transfer mechanism for the inhibition reaction, we provided mechanistic insight for the action of traditional irreversible inhibitors that are effective and now better understood drugs. It is reasonable to expect that the results offered here should open the door towards designing more effective MAO inhibitors as transition-state analogues devoid of adverse effects. This is particularly important since mechanismbased inhibitors provide the most specific type of inhibitors, because the enzyme has not only to recognize and bind the inhibitor; it also has to perform a part of its normal catalytic function to generate an activated species that then reacts with the enzyme. This means that there are, at least, two factors to be optimized to obtain high 
selectivity and potency - the affinity of the enzyme for the non-covalent inhibitor binding and the rates of the subsequent steps leading to the irreversible inactivation. These two factors should ideally co-operate, where a higher binding affinity is further enhanced by a higher reactivity to give the adduct. Hopefully, our computational results could guide in both directions.

\section{ASSOCIATED CONTENT}

Supporting Information. Full details of the simulation setup, Cartesian coordinates for computed stationary points, various graphical analyses of molecular dynamics trajectories, graphical representation of the contribution of active site residues towards the overall binding free energies, free energy profiles with ionized Lys296 residue, charge distribution and geometries during the rate-limiting hydride abstraction step with rasagiline.

\section{AUTHOR INFORMATION}

\section{Corresponding Author}

*Tel.: +385-1-4561117; E-mail: robert.vianello@irb.hr

\section{Author Contributions}

T. Tandarić performed the research and analyzed the data. R. Vianello designed and supervised the research, analyzed the data and wrote the manuscript. Both authors discussed the results and reviewed the manuscript.

\section{Funding}

This work benefited from the financial support by the Croatian Science Foundation under grant IP-2014-09-3386.

\section{Notes}

The authors declare no competing financial interest.

\section{ACKNOWLEDGMENTS}

We thank the University of Zagreb Computing Centre (SRCE) for granting computational resources on the ISABELLA cluster. We would also like to thank Prof. Janez Mavri for a useful discussion and critical reading of the manuscript. 


\section{REFERENCES}

[1] J. Grimsby, N. C. Lan, R. Neve, K. Chen, J. C. Shih, Tissue distribution of human monoamine oxidase A and B mRNA. J. Neurochem. 1990, 55, 1166-1169.

[2] a) J. C. Shih, K. Chen, M. J. Ridd, Monoamine oxidase: from genes to behavior. Annu. Rev. Neurosci, 1999, 22, 197-217; b) K. N. Westlund, R. M. Denney, L. M. Kochersperger, R. M. Rose, C. W. Abell, Distinct monoamine oxidase A and B populations in primate brain. Science 1985, 230, 181-183.

[3] W. Weyler, Y. P. P. Hsu, X. O. Breakefield, Biochemistry and genetics of monoamine-oxidase. Pharmacol. Ther. 1990, 47, 391-417.

[4] L. De Colibus, M. Li, C. Binda, A. Lustig, D. E. Edmondson, A. Mattevi, Three-dimensional structure of human monoamine oxidase A (MAO A): relation to the structures of rat MAO A and human MAO B. Proc. Natl. Acad. Sci. U. S. A. 2005, 102, 12684-12689.

[5] C. J. Fowler, K. F. Tipton, On the substrate specificities of 2 forms of monoamine oxidase. J. Pharm. Pharmacol. 1984, 36, 111-115.

[6] S. Deshwal, M. Di Sante, F. Di Lisa, N. Kaludercic, Emerging role of monoamine oxidase as a therapeutic target for cardiovascular disease. Curr. Opin. Pharmacol. 2017, 33, 64-69.

[7] P. Jenner, Oxidative stress in Parkinson's disease. Ann Neurol. 2003, 53 Suppl 3, S26-S36; discussion S36S38.

[8] M. Pavlin, M. Repič, R. Vianello, J. Mavri, The chemistry of neurodegeneration: kinetic data and their implications. Mol. Neurobiol. 2016, 53, 3400-3415.

[9] M. B. Youdim, D. E. Edmondson, K. F. Tipton, The therapeutic potential of monoamine oxidase inhibitors. Nat. Rev. Neurosci. 2006, 7, 295-309.

[10] a) N. I. Dubrovina, N. K. Popova, M. A. Gilinskii, R. A. Tomilenko, I. Seif, Acquisition and extinction of a conditioned passive avoidance reflex in mice with genetic knockout of monoamine oxidase A. Neurosci. Behav. Physiol. 2006, 36, 335-339; b) M. Lee, K. Chen, J. C. Shih, N. Hiroi, MAO-B knockout mice exhibit deficient habituation of locomotor activity but normal nicotine intake. Genes Brain Behav. 2004, 3, $216-227$.

[11] M. Bortolato, J. C. Shih, Behavioral outcomes of monoamine oxidase deficiency: Preclinical and clinical evidence. Int. Rev. Neurobiol. 2011, 100, 13-42.

[12] a) A. C. Tripathi, S. Upadhyay, S. Paliwal, S. K. Saraf, Privileged scaffolds as MAO inhibitors: Retrospect and prospects. Eur. J. Med. Chem. 2018, 145, 445-497; b) C. D. Monte, M. D'Ascenzio, P. Guglielmi, V. 
Mancini, S. Carradori, Opening New Scenarios for Human MAO Inhibitors. Cent. Nerv. Syst. Agents. Med. Chem. 2016, 16, 98-104; c) J. P. M. Finberg, J. M. Rabey, Inhibitors of MAO-A and MAO-B in Psychiatry and Neurology. Front. Pharmacol. 2016, 7, 340; d) G. Di Giovanni, D. Švob Štrac, M. Sole, M. Unzeta, K. F. Tipton, D. Mück-Šeler, I. Bolea, L. Della Corte, M. Nikolac Perković, N. Pivac, I. J. Smolders, A. Stasiak, W. A. Fogel, P. De Deurwaerdère, Monoaminergic and Histaminergic Strategies and Treatments in Brain Diseases. Front. Neurosci. 2016, 10, 541; e) P. Riederer, T. Müller, Monoamine oxidase-B inhibitors in the treatment of Parkinson's disease: clinical-pharmacological aspects. J. Neural Transm. 2018, 125, 1751-1757; f) K. F. Tipton, G. P. Davey, A. G. McDonald, Kinetic Behavior and Reversible Inhibition of Monoamine Oxidases - Enzymes that Many Want Dead. Int. Rev. Neurobiol. 2011, 100, 43-64.

[13] H. H. Fox, J. T. Gibas, Synthetic tuberculostats. V. Alkylidene derivatives of isonicotinylhydrazine. J. Org. Chem. 1953, 18, 983-989.

[14] J. Saura, E. Nadal, B. van den Berg, M. Vila, J. A. Bombi, N. Mahy, Localization of monoamine oxidases in human peripheral tissues. Life Sci. 1996, 59, 1341-1349.

[15] A. M. Asatoor, A. J. Levi, M. D. Milne, Tranylcypromine and cheese. Lancet 1963, 2, 733-734.

[16] É. Szökő, T. Tábi, P. Riederer, L. Vécsei, K. Magyar, Pharmacological aspects of the neuroprotective effects of irreversible MAO-B inhibitors, selegiline and rasagiline, in Parkinson's disease. J. Neural Transm. 2018, 125, 1735-1749.

[17] a) A. H. Schapira, Progress in neuroprotection in Parkinson's disease. Eur. J. Neurol. 2008, 15 (Suppl 1), 513; b) O. Weinreb, T. Amit, O. Bar-Am, M. B. Youdim, Rasagiline: a novel anti-Parkinsonian monoamine oxidase-B inhibitor with neuroprotective activity. Prog. Neurobiol. 2010, 92, 330-344.

[18] J. Saura Marti, R. Kettler, M. Da Prada, J. G. Richards, Molecular neuroanatomy of MAO-A and MAO-B. J. Neural. Transm. Suppl. 1990, 32, 49-53.

[19] C. Binda, E. M. Milczek, D. Bonivento, J. Wang, A. Mattevi, D. E. Edmondson, Lights and shadows on monoamine oxidase inhibition in neuroprotective pharmacological therapies. Curr. Top. Med. Chem. 2011, $11,2788-2796$.

[20] R. R. Ramsay, Inhibitor design for monoamine oxidases. Curr. Pharm. Des. 2013, 19, 2529-2539.

[21] a) R. R. Ramsay, Molecular aspects of monoamine oxidase B. Prog. Neuropsychopharmacol. Biol. Psychiatry. 2016, 69, 81-89; b) S. De Cesco, J. Kurian, C. Dufresne, A. K. Mittermaier, N. Moitessier, Covalent inhibitors design and discovery. Eur. J. Med. Chem. 2017, 138, 96-114.

[22] J. Knoll, (-)Deprenyl (Selegiline): past, present and future. Neurobiology 2000, 8, 179-199. 
[23] H. Y. K. Chuang, D. R. Patek, L. Hellerma, Mitochondrial monoamine oxidase - inactivation by pargyline - adduct formation. J. Biol. Chem. 1974, 249, 2381-2384.

[24] a) C. Binda, P. Newton-Vinson, F. Hubalek, D. E. Edmondson, A. Mattevi, Structure of human monoamine oxidase B, a drug target for the treatment of neurological disorders. Nat. Struct. Biol. 2002, 9, 22-26; b) D. E. Edmondson, C. Binda, J. Wang, A. K. Upadhyay, A. Mattevi, Molecular and mechanistic properties of the membrane-bound mitochondrial monoamine oxidases. Biochemistry 2009, 48, 4220-4230.

[25] a) T. Kamada, T. Chow, T. Hiroi, S. Imaoka, K. Morimoto, H. Ohde, Y. Funae, Metabolism of selegiline hydrochloride, a selective monoamine b-type inhibitor, in human liver microsomes. Drug. Metab. Pharmacokinet. 2002, 17, 199-206; b) J. J. Chen, D. M. Swope, Clinical pharmacology of rasagiline: a novel, second generation propargylamine for the treatment of Parkinson disease. J. Clin. Pharmacol. 2005, $45,878-894$.

[26] a) S. J. Simmons, J. M. Leyrer-Jackson, C. F. Oliver, C. Hicks, J. W. Muschamp, S. M. Rawls, M. F. Olive, DARK Classics in Chemical Neuroscience: Cathinone-Derived Psychostimulants. ACS Chem. Neurosci. 2018, 9, 2379-2394; b) I. dela Peña, R. Gevorkiana, W.-X. Shi, Psychostimulants affect dopamine transmission through both dopamine transporter-dependent and independent mechanisms. Eur. J. Pharmacol. 2015, 764, 562-570; c) N. Umek, B. Geršak, N. Vintar, M. Šoštarič, J. Mavri, Dopamine Autoxidation Is Controlled by Acidic pH. Front. Mol. Neurosci. 2018, 11, 467.

[27] S. Mandel, O. Weinreb, T. Amit, M. B. Youdim, Mechanism of neuroprotective action of the anti-Parkinson drug rasagiline and its derivatives. Brain. Res. Rev. 2005, 48, 379-387.

[28] a) A. J. Azzaro, J. Ziemniak, E. Kemper, B. J. Campbell, C. VanDenBerg, Pharmacokinetics and absolute bioavailability of selegiline following treatment of healthy subjects with the selegiline transdermal system (6 mg/24 h): a comparison with oral selegiline capsules. J. Clin. Pharmacol. 2007, 47, 1256-1267; b) Z. Chuanjun, Z. Xiaodong, J. Ronghuan, J. Feng, S. Zhonghua, X. Rong, Z. Yuying, Comparison for efficacy and tolerability among ten drugs for treatment of Parkinson's disease: A network meta-analysis. Sci. Rep. 2017, 7, 45865 .

[29] D. Robakis, S. Fahn, Defining the role of the monoamine oxidase-B inhibitors for Parkinson's disease. CNS Drugs 2015, 29, 433-441.

[30] a) L. Pisani, R. Farina, O. Nicolotti, D. Gadaleta, R. Soto-Otero, M. Catto, M. Di Braccio, E. MendezAlvarez, A. Carotti, In silico design of novel 2H-chromen-2-one derivatives as potent and selective MAO-B inhibitors. Eur. J. Med. Chem. 2015, 89, 98-105; b) L. Pisani, R. Farina, M. Catto, R. M. Iacobazzi, O. Nicolotti, S. Cellamare, G. F. Mangiatordi, N. Denora, R. Soto-Otero, L. Siragusa, C.D. Altomare, A. Carotti, Exploring basic tail modifications of coumarin based dual acetylcholinesterase-monoamine oxidase 
B inhibitors: Identification of water-soluble, brain permeant neuroprotective multitarget agents. J. Med. Chem. 2016, 59, 6791-6806.

[31] a) N. Gökhan-Kelekçi, S. Koyunoğlu, S. Yabanoğlu, K. Yelekçi, Ö. Özgen, G. Uçar, K. Erol, E. Kendi, A. Yeşilada, New pyrazoline bearing $4(3 \mathrm{H})$-quinazolinone inhibitors of monoamine oxidase: synthesis, biological evaluation, and structural determinants of MAO-A and MAO-B selectivity. Bioorg. Med. Chem. 2009, 17, 675-689; b) Z.-M. Wang, X.-M. Li, G.-M. Xue, W. Xu, X.-B. Wang, L.-Y. Kong, Synthesis and evaluation of 6-substituted 3-arylcoumarin derivatives as multifunctional acetylcholinesterase/ monoamine oxidase B dual inhibitors for the treatment of Alzheimer's disease. RSC Adv. 2015, 5, 104122-104137.

[32] a) M. J. Matos, D. Viña, E. Quezada, C. Picciau, G. Delogu, F. Orallo, L. Santana, E. Uriarte, A new series of 3-phenylcoumarins as potent and selective MAO-B inhibitors. Bioorg. Med. Chem. Lett. 2009, 19, 32683270; b) M. J. Matos, D. Viña, P. Janeiro, F. Borges, L. Santana, E. Uriarte, New halogenated 3phenylcoumarins as potent and selective MAO-B inhibitors. Bioorg. Med. Chem. Lett. 2010, 20, $5157-$ 5160.

[33] G. Felice Mangiatordi, D. Alberga, L. Pisani, D. Gadaleta, D. Trisciuzzi, R. Farina, A. Carotti, G. Lattanzi, M. Catto, O. Nicolotti, A rational approach to elucidate human monoamine oxidase molecular selectivity. Eur. J. Pharm. Sci. 2017, 101, 90-99.

[34] M. De Vivo, M. Masetti, G. Bottegoni, A. Cavalli, Role of molecular dynamics and related methods in drug discovery. J. Med. Chem. 2016, 59, 4035-4061.

[35] a) P. E. M. Siegbahn, F. Himo, Recent developments of the quantum chemical cluster approach for modeling enzyme reactions. J. Biol. Inorg. Chem. 2009, 14, 643-651; b) F. Himo, Recent trends in quantum chemical modeling of enzymatic reactions. J. Am. Chem. Soc. 2017, 139, 6780-6786; c) P. E. M. Siegbahn, F. Himo, The quantum chemical cluster approach for modeling enzyme reactions. WIREs Comput. Mol. Sci. 2011, 1, 323-336; d) G. C. Patton, P. Stenmark, D. R. Gollapalli, R. Sevastik, P. Kursula, S. Flodin, H. Schuler, C. T. Swales, H. Eklund, F. Himo, P. Nordlund, L. Hedstrom, Cofactor mobility determines reaction outcome in the IMPDH and GMPR $(\beta-\alpha) 8$ barrel enzymes. Nat. Chem. Biol. 2011, 7, 950-958; e) M. R. A. Blomberg, T. Borowski, F. Himo, R.-Z. Liao, P. E. M. Siegbahn, Quantum chemical studies of mechanisms for metalloenzymes, Chem. Rev. 2014, 114, 3601-3658; f) M. G. Quesne, T. Borowski, S. P. de Visser, Quantum mechanics/molecular mechanics modeling of enzymatic processes: caveats and breakthroughs, Chem. Eur. J. 2016, 22, 2562-2581; g) S. F. Sousa, A. J. M. Ribeiro, R. P. P. Neves, N. F. Brás, N. M. F. S. A. Cerqueira, P. A. Fernandes, M. J. Ramos, Application of quantum mechanics/molecular mechanics methods in the study of enzymatic reaction mechanisms, WIREs Comput. 
Mol. Sci. 2017, 7, e1281; h) M. G. Quesne, F. Silveri, N. H. de Leeuw, C. R. A. Catlow, Advances in sustainable catalysis: a computational perspective, Front. Chem. 2019, 7, 182.

[36] N. Homeyer, H. Gohlke, Free energy calculations by the molecular mechanics Poisson-Boltzmann surface area method. Mol. Inform. 2012, 31, 114-122.

[37] a) W. J. Geldenhuys, K. S. Ko, H. Stinnett, C. J. Van der Schyf, M. H. Lim, Identification of multifunctional small molecule-based reversible monoamine oxidase inhibitors. Med. Chem. Commun. 2011, 2, 1099-1103; b) M. Toprakçi, K. Yelekçi, Docking studies on monoamine oxidase-B inhibitors: Estimation of inhibition constants (Ki) of a series of experimentally tested compounds. Bioorganic Med. Chem. Lett. 2005, 15, 4438-4446.

[38] M. Tavari, S. F. Malan, J. Joubert, Design, synthesis, biological evaluation and docking studies of sulfonyl isatin derivatives as monoamine oxidase and caspase-3 inhibitors. Med. Chem. Commun. 2016, 7, 16281639.

[39] a) Y. Li, X. Qiang, L. Luo, Y. Li, G. Xiao, Z. Tan, Y. Deng, Synthesis and evaluation of 4-hydroxyl aurone derivatives as multifunctional agents for the treatment of Alzheimer's disease. Bioorganic Med. Chem. 2016, 24, 2342-2351; b) Y. Li, X. Qiang, L. Luo, X. Yang, G. Xiao, Y. Zheng, Z. Cao, Z. Sang, F. Su, Y. Deng, Multitarget drug design strategy against Alzheimer's disease: Homoisoflavonoid Mannich base derivatives serve as acetylcholinesterase and monoamine oxidase B dual inhibitors with multifunctional properties. Bioorganic Med. Chem. 2017, 25, 714-726.

[40] a) G. Jo, S. Ahn, B.-G. Kim, H. R. Park, Y. H. Kim, H. A. Choo, D. Koh, Y. Chong, J.-H. Ahn, Y. Lim, Chromenylchalcones with inhibitory effects on monoamine oxidase B. Bioorganic Med. Chem. 2013, 21, 7890-7897; b) H. R. Park, J. Kim, T. Kim, S. Jo, M. Yeom, B. Moon, I. H. Choo, J. Lee, E. J. Lim, K. D. Park, S.-J. Min, G. Nam, G. Keum, C. J. Lee, H. Choo, Oxazolopyridines and thiazolopyridines as monoamine oxidase B inhibitors for the treatment of Parkinson's disease. Bioorganic Med. Chem. 2013, 21, $5480-5487$

[41] R. Borštnar, M. Repič, S. C. L. Kamerlin, R. Vianello, J. Mavri, Computational study of the pKa values of potential catalytic residues in the active site of monoamine oxidase B. J. Chem. Theory Comput. 2012, 8 , $3864-3870$.

[42] M. Li, C. Binda, A. Mattevi, D. E. Edmondson, Functional role of the "aromatic cage" in human monoamine oxidase B: Structures and catalytic properties of Tyr435 mutant proteins. Biochemistry 2006, $45,4775-4784$. 
[43] A. Maršavelski, R. Vianello, What a difference a methyl group makes: The selectivity of monoamine oxidase B towards histamine and $N$-methylhistamine. Chem. Eur. J. 2017, 23, 2915-2925.

[44] R. M. Geha, I. Rebrin, K. Chen, J. C. Shih, Substrate and inhibitor specificities for human monoamine oxidase A and B are influenced by a single amino acid. J. Biol. Chem. 2001, 276, 9877-9882.

[45] R. M. Geha, K. Chen, J. Wouters, F. Ooms, J. C. Shih, Analysis of conserved active site residues in monoamine oxidase A and B and their three-dimensional molecular modeling. J. Biol. Chem. 2002, 277, 17209-17216.

[46] a) D. Bonivento, E. M. Milczek, G. R. McDonald, C. Binda, A. Holt, D. E. Edmondson, A. Mattevi, Potentiation of ligand binding through cooperative effects in monoamine oxidase B. J. Biol. Chem. 2010, 285, 36849-36856; b) F. Hubálek, C. Binda, A. Khalil, M. Li, A. Mattevi, N. Castagnoli, D. E. Edmondson, Demonstration of isoleucine 199 as a structural determinant for the selective inhibition of human monoamine oxidase B by specific reversible inhibitors. J. Biol. Chem. 2005, 280, 15761-15766.

[47] E. M. Milczek, C. Binda, S. Rovida, A. Mattevi, D. E. Edmondson, The "gating" residues Ile199 and Tyr326 in human monoamine oxidase B function in substrate and inhibitor recognition. FEBS J. 2011, 278, $4860-4869$.

[48] C. Binda, F. Hubalek, M. Li, Y. Herzig, J. Sterling, D. E. Edmondson, A. Mattevi, Crystal structures of monoamine oxidase B in complex with four inhibitors of the $\mathrm{N}$-propargylaminoindan class. J. Med. Chem. 2004, 47, 1767-1774.

[49] M. L. Hare, Tyramine oxidase: a new enzyme system in liver. Biochem. J. 1928, 22, 968-979.

[50] K. F. Tipton, 90 years of monoamine oxidase: some progress and some confusion. J. Neural Transm. 2018, $125,1519-1551$.

[51] C. Binda, M. Li, F. Hubalek, N. Restelli, D. E. Edmondson, A. Mattevi, Insights into the mode of inhibition of human mitochondrial monoamine oxidase B from high-resolution crystal structures. Proc. Natl. Acad. Sci. U.S.A. 2003, 100, 9750-9755.

[52] R. Vianello, M. Repič, J. Mavri, How are biogenic amines metabolized by monoamine oxidases? Eur. J. Org. Chem. 2012, 7057-7065.

[53] P. Macheroux, S. Ghisla, C. Sanner, H. Ruterjans, F. Muller, Reduced flavin: NMR investigation of N(5)-H exchange mechanism, estimation of ionisation constants and assessment of properties as biological catalyst. BMC Biochem. 2005, 6, 26-36. 
[54] M. Smith, J. March, March's advanced organic chemistry: reactions, mechanisms and structure, 5th ed., Wiley, New York, 2001.

[55] M. Repič, R. Vianello, M. Purg, F. Duarte, P. Bauer, S. C. L. Kamerlin, J. Mavri, Empirical valence bond simulations of the hydride transfer step in the monoamine oxidase B catalyzed metabolism of dopamine. Proteins 2014, 82, 3347-3355.

[56] a) J. Mavri, R. A. Matute, Z. T. Chu, R. Vianello, Path integral simulation of the H/D kinetic isotope effect in monoamine oxidase B catalyzed decomposition of dopamine. J. Phys. Chem. B 2016, 120, 3488-3492; b) M. Poberžnik, M. Purg, M. Repič, J. Mavri, R. Vianello, Empirical valence bond simulations of the hydridetransfer step in the monoamine oxidase A catalyzed metabolism of noradrenaline. J. Phys. Chem. B 2016, 120, 11419-11427; c) G. Oanca, J. Stare, R. Vianello, J. Mavri, Multiscale simulation of monoamine oxidase catalyzed decomposition of phenylethylamine analogs. Eur. J. Pharmacol. 2017, 817, 46-50.

[57] a) G. Zapata-Torres, A. Fierro, G. Barriga-González, J. C. Salgado, C. Celis-Barros, Revealing monoamine oxidase B catalytic mechanisms by means of the quantum chemical cluster approach. J. Chem. Inf. Model. 2015, 55, 1349-1360; b) V. Atalay, S. S. Erdem, A comparative computational investigation on the proton and hydride transfer mechanisms of monoamine oxidase using model molecules. Comp. Biol. Chem. 2013, 47, 181-191.

[58] J. R. Tormos, M. B. Suarez, P. F. Fitzpatrick, ${ }^{13} \mathrm{C}$ kinetic isotope effects on the reaction of a flavin amine oxidase determined from whole molecule isotope effects. Arch. Biochem. Biophys. 2016, 612, 115-119.

[59] R. R. Ramsay, A. Albreht, Kinetics, mechanism, and inhibition of monoamine oxidase. J. Neural Transm. 2018, 125, 1659-1683.

[60] F. Hubalek, C. Binda, M. Li, Y. Herzig, J. Sterling, M. B. Youdim, A. Mattevi, D. E. Edmondson, Inactivation of purified human recombinant monoamine oxidases A and B by rasagiline and its analogues. J. Med. Chem. 2004, 47, 1760-1766.

[61] R. Vianello, N. Peran, Z. B. Maksić, Hydride affinities of some substituted alkynes: Prediction by DFT calculations and rationalization by triadic formula. J. Phys. Chem. A 2006, 110, 12870-12881.

[62] A. Albreht, I. Vovk, J. Mavri, J. Marco-Contelles, R. R. Ramsay, Evidence for a cyanine link between propargylamine drugs and monoamine oxidase clarifies the inactivation mechanism. Front. Chem. 2018, 6 , 169.

[63] R. B. Silverman, Radical ideas about monoamine oxidase. Acc. Chem. Res. 1995, 28, 335-342.

[64] a) G. Gadda, Oxygen activation in flavoprotein oxidases: the importance of being positive. Biochemistry 2012, 51, 2662-2669; b) M. Henderson Pozzi, P. F. Fitzpatrick, A lysine conserved in the monoamine 
oxidase family is involved in oxidation of the reduced flavin in mouse polyamine oxidase. Arch. Biochem. Biophys. 2010, 498, 83-88.

[65] A. Prah, E. Frančišković, J. Mavri, J. Stare, Electrostatics as the driving force behind the catalytic function of the monoamine oxidase A enzyme confirmed by quantum computations. ACS Catal. 2019, 9, 1231-1240.

[66] M. Repič, M. Purg, R. Vianello, J. Mavri, Examining electrostatic preorganization in monoamine oxidases A and B by structural comparison and $\mathrm{p} K_{\mathrm{a}}$ calculations. J. Phys. Chem B 2014, 118, 4326-4332. 